\title{
POZNAVANJE TRIGLAVSKEGA NARODNEGA PARKA
}

\author{
Tina Velkavrh*
}

Izvleček

UDK 502.72(497.4 Triglavski narodni park)

Prispevek prikazuje poznavanje Triglavskega narodnega parka pri srednješolcih Zavoda za invalidno mladino $v$ Kamniku in primerja njihovo percepcijo $z$ mladimi sovrstniki $v$ Triglavskem narodnem parku. Izpostavljeno je poznavanje smotra, obsega, števila prebivalcev, zaščitenih rastlin in živali parka.

Ključne besede: Triglavski narodni park

COMPREHENSION OF THE TRIGLAV NATIONAL PARK

\section{Abstract}

The paper reflects perception of Triglav National Park among students of secondary school at Center for Training of the Disabled Youth, Kamnik and compares their knowledge with young from the area of Triglav National Park. The emphasis is on the reason for existence and its purpose, physical size, number of inhabitants and the protected flora and fauna.

Key words: Triglav national park

\footnotetext{
* Dipl. geog. in fil., Zavod za invalidno mladino Kamnik -SŠ, Novi trg 43a, 1240 Kamnik
} 


\section{UVOD}

Percepcija okolja je odvisna od stopnje poznavanja okoljskih procesov. Okoljsko zavest bi bilo potrebno razvijati že pri predšolskih in osnovnošolskih otrocih. V srednji šoli imajo mladi bolj izoblikovan pogled na svet, vendar so še dovolj dojemljivi za nove informacije.

V letošnjem šolskem letu (1998/1999) se na Zavodu za invalidno mladino v Kamniku izvaja program "Znanje pripomore k varovanju okolja”, ki ga sofinancira Ministrstvo za šolstvo in šport. Namen programa je osvestiti dijake udeležence programa, njihove sošolce, starše in sovrstnike o načinih varovanja okolja. Naravno in kulturno krajino kjer se nahajajo vrednote nacionalnega pomena, lahko zavarujemo kot narodni park. Zanimalo nas je, kako učenci zavoda in mladi $\mathrm{v}$ Triglavskem narodnem parku percepirajo park, zato smo v programu izvedli tudi anketo o poznavanju Triglavskega narodnega parka.

Namen prispevka je s pomočjo ankete pokazati stopnjo poznavanja Triglavskega narodnega parka pri srednješolcih Zavoda za invalidno mladino $\mathrm{v} \mathrm{Kamniku}^{1}$ in mladimi sovrstniki v parku.

\section{TRIGLAVSKI NARODNI PARK}

Posebej varovana območje so namenjena izjemnim značilnim, estetskim elementom, kjer to prispeva k biološkemu ravnotežju v pokrajini (zatočišče ogroženih rastlinskih in živalskih vrst), objektom in območjem kulturnozgodovinskega pomena.

Varovana območja se ločijo glede velikosti in režima varovanja. Po mednarodni kategoriji poznamo pet varovanih območij, ki se vrstijo od pokrajin kamor naj človek ne posega do kulturne krajine.

Po zakonu o narodni in kulturni dediščini (Ul SRS 1981, 17 člen) je narodni park večje, naravno zaokroženo pretežno prvobitno območje z ekosistemi in naravnimi znamenitostmi velikega ali izjemnega pomena. Namenjeni so predvsem ohranitvi in

\footnotetext{
1 Srednja šola z vzgojno izobraževalnimi programi: monter električnih naprav (dvoletni program), elektrikar (triletni program), poslovni tajnik (triletni program) in upravni tehnik (štiriletni program).Oblike in metode dela so prilagojene specifičnim potrebam dijakov, ki se izobražujejo v oddelkih z največ dvanajst dijaki. Letos šolo obiskuje 172 dijakov, od tega jih 87 ne prebiva $v$ zavodu.
} 
preučevanju naravnih ekosistemov in rekreaciji. Najvišja pristojna oblast ima nalogo, da prepreči škodljive posege. Obiskovalci lahko vstopajo pod posebnimi pogoji.

Po zakonu o Triglavskem narodnem parku iz leta 1981 je bil narodni park ustanovljen $\mathrm{z}$ namenom, da se ohranijo izjemne naravne in kulturne vrednote, zavarujejo avtohtono rastlinstvo, živalstvo in naravni ekosistemi ter značilnosti neživega sveta, zagotovita $\mathrm{z}$ naravnimi danostmi usklajen nadaljni razvoj kmetijstva in gozdarstva, ohrani in razvija kulturna krajina ter zagotovijo razvoj in materialni in drugi pogoji za življenje in delo prebivalcev $\mathrm{v}$ osrednjem delu Julijskih Alp, omogočita delovnim ljudem in drugim občanom ter drugim obiskovalcem uživanje naravnih in kulturnih vrednot ter rekreacijo $\mathrm{v}$ naravi $\mathrm{v}$ tem prostoru in dopolni dosedajne varovanje.

Današnji obseg je Triglavski narodni park (TNP) dobil 1981- 83807 ha, zajema skoraj celotne Julijske Alpe kar predstavlja 4\% ozemlja Slovenije. Stalnih prebivalcev je le tisočinka vseh Slovencev, njihovo število še vedno pada, kljub že v Ustavi posvečeni posebni skrbi (71 člen) prebivalstvu slabo dostopnih in hribovskih območij. Vendar to ne pomeni, da je park slabo obljuden, večkrat imamo celo občutek, da je ljudi preveč. Poleg lastnikov počitniških hiš TNP obišče veliko izletnikov in turistov.

Triglavski narodni park je nastal tudi z namenom, da bi zagotavljal uživanje naravnih in kulturnih vrednot in rekreacijo v naravi (Zakon o Triglavskem narodnem parku, (Ul št. 17, 1981, 1. člen ).Vendar množičnii turizem prinaša vrsto okoljskih problemov in lahko degradira vrednote zaradi katerih je park nastal. Obisk mora biti zato podrejen varstvu narave in kulturnih vrednot, zavarovanju avtohtonega rastlinstva, živalstva in naravnih ekosistemov. V smernicah IUCN (Mednarodna zveza za ohranitev narave in naravnih dobrin) je zapisano, da mora biti rekreacija podrejena varstvu narave. Stalni prebivalci ne smejo občutiti parka kot nekaj, kar je namenjeno le obiskovalcem.

Stopnja degradacije v Triglavskem narodnem parku bi se lahko bistveno zmanjšala če bi bili domačini in obiskovalci bolje seznanjeni z vrednotami parka.

\begin{abstract}
ANKETA
Po podatkih ankete (Velkavrh, 1996), ki je ugotavljala okoljsko osveščenost v Triglavskem narodnem parku, nekateri obiskovalci ne poznajo namena parka. Podan je primer anketirane maturantke, ki je menila, da je narodni park oblikovana krajina, kjer ne sme manjkati urejenih zelenih površin in rekreacijskih objektov.
\end{abstract}


Z anketnimi vrašanji smo ponovno želeli osvetliti poznavanje parka. Primerjali smo poznavanje Triglavskega narodnega parka pri sredenješolcih Zavoda za invalidno mladino v Kamniku in mladimi sovrstniki v Triglavskem narodnem parku.

V anketi, ki smo jo poimenovali “ Kako poznam Triglavski narodni park?”, smo postavili štiri vprašanja. Pri vprašanjih smo pričakovali zelo širok spekter odgovorov, tudi zelo nenavadne.

Od anketirancev smo želeli izvedeti smoter, obseg, oceno poseljenosti in poznavanja rastlin in živali Triglavskega narodnega parka. Anketirancem smo postavili naslednja vprašanja:

- Kaj je po tvojem mnenju Triglavski narodni park?

- Obkroži naselja, ke se nahajajo v Triglavskem narodnem parku: Idrija, Žiri, Stara Fužina, Koprivnik, Bled, Čadrg, Tolmin, Tolminske Ravne, Trenta, Bovec

- Koliko ljudi živi v Triglavskem narodnem parku?

- Ali veš katere rastlinske in živalske vrste so ogrožene in jih je torej prepovedano nabirati (loviti, drugače ogrožati)?

\section{ANKETIRAN.JE}

Anketiranje je potekalo v dveh fazah. Na začetku šolskega leta 1998-1999 je bilo anketiranih dvajset naključno izbranih učencev srednje šole Zavoda za invalidno mladino v Kamniku*.

Učenci zavoda, udeleženci programa Znanje pripomore $\mathrm{k}$ varovanju okolja, so v ponedeljek, 26.10. 1998, na terenskem delu v Ribčevem Lazu, Stari Fužini in Studorju anketirali dvajset naključno izbranih sovrstnikov (starih od petnajst do dvajset let). 


\section{REZULTATI ANKETE}

\section{Smoter Triglavskega narodnega parka}

Največ mladih je Triglavski park opredelilo kot območje varovane narave $(37,5 \%)$, predvsem rastlin in živali in zavarovano območje kjer se vsako nepravilno ravnanje sankcionira $(25 \%)$.

Anketiranci, med katerimi je bilo več učencev zavoda, so park opredelili tudi kot abstraktno kategorijo lepega in ozemlje, ki je namenjeno turistom.

Graf 1: Namen Triglavskega narodnega parka The purpose of Triglav National Park

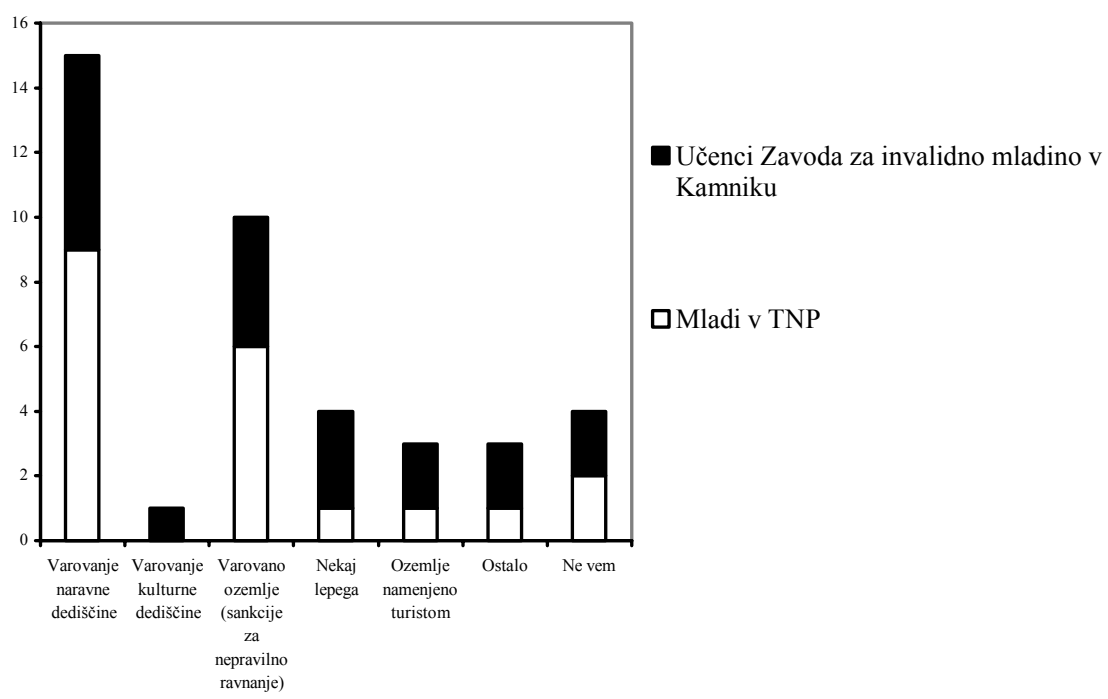




\section{Obseg Triglavskega narodnega parka}

Mladi so morali med navedenimi naselji izbrati tiste, ki se nahajajo v Triglavskem narodnem parku.

Tabela 1: Prikaz naselij, ki so jih anketiranci locirali v Triglavski narodni park

\begin{tabular}{|l|c|c|}
\hline & $\begin{array}{c}\text { Mladi } \\
\text { v TNP }\end{array}$ & $\begin{array}{c}\text { Učenci Zavoda za } \\
\text { invalidno mladino } \\
\text { v Kamniku }\end{array}$ \\
\hline $\begin{array}{l}\text { Naselja, ki se nahajajo v } \\
\text { Triglavskem narodnem parku }\end{array}$ & 18 & 10 \\
\hline Stara Fužina & 17 & 1 \\
\hline Koprivnik & 1 & 1 \\
\hline Čadrg & 12 & 7 \\
\hline Tolminske Ravne & 17 & 18 \\
\hline Trenta & $\mathbf{6 5}$ & $\mathbf{4 1}$ \\
\hline SKUPAJ & & \\
\hline $\begin{array}{l}\text { Naselja, ki se ne nahajajo } \\
\text { Triglavskem narodnem parku }\end{array}$ & 3 & 4 \\
\hline Idrija & 1 & 3 \\
\hline Žiri & 1 & 3 \\
\hline Bled & 15 & 6 \\
\hline Tolmin & 16 & 9 \\
\hline Bovec & $\mathbf{4 6}$ & $\mathbf{4 1}$ \\
\hline SKUPAJ & & \\
\hline
\end{tabular}

Domačini so pravilneje opredelili naselja, ki se nahajajo v Triglavskem narodnem parku. Razlika med anketiranima skupinama je posebno vidna pri Stari Fužini in Koprivniku. 


\section{Poznavanje števila prebivalcev Triglavskega narodnega parka}

Tabela 2: Ocena števila prebivalcev v Triglavskem narodnem parku

\begin{tabular}{|l|l|c|c|}
\hline $\begin{array}{l}\text { Odstopanje } \\
\text { ocen }\end{array}$ & Mladi v TNP & $\begin{array}{c}\text { Učenci Zavoda za } \\
\text { invalidno mladino v } \\
\text { Kamniku }\end{array}$ \\
\hline 3. & 0 & 0 & 4 \\
\hline 2. & $1-1000$ & 3 & 6 \\
\hline 1. & $1001-3000$ & 5 & 1 \\
\hline 2. & $3001-10000$ & 7 & 1 \\
\hline 3. & Več kot 10000 & 4 & 3 \\
\hline & Ne vem & 1 & 4 \\
\hline
\end{tabular}

Odstopanje števila prebivalcev $\mathrm{v}$ Triglavskem narodnem parku lahko ponazorimo $\mathrm{z}$ razredi. V prvem razredu se ocene najbolj približajo dejanskemu stanju, najbolj se razhajajo v tretji skupini.

Graf 2: Ocena števila prebivalcev v Triglavskem narodnem parku prikazana $\mathrm{z}$ razredi The accuracy of assessment on number of inhabitants of TNP

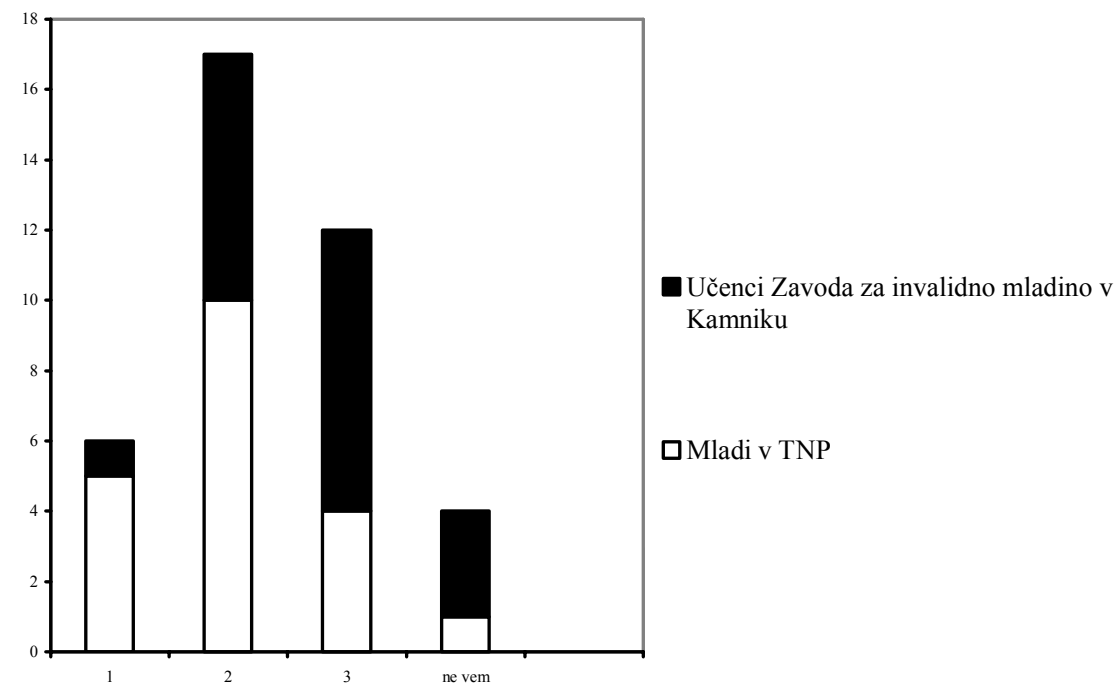

Pravilneje so število prebivalcev opredeljevali domačini ( 1 . skupina $25 \%$, 2. skupina 
$50 \%$, 3. skupina $20 \%$ ) kot srednješolci zavoda (1. skupina $5 \%$, 2. skupina $35 \%, 3$. skupina $40 \%$ ).

\section{Poznavanje ogroženih rastlinskih in živalskih vrst Triglavskega narodnega parka}

Anketiranci so pogosteje imenovali naslednje rastlinske vrste: planiko $(60 \%$ domačinov, 30\% učencev zavoda) murko, encijan in živalske vrste: gamsa, kozoroga, medveda, orla svizca in zlatoroga.

Mladi iz Triglavskega parka so navedli več ogroženih rastlin in živali, poznali so tudi več različnih vrst (mladi iz parka 17, domačini 13).

\section{ANALIZA REZULTATOV ANKETE}

\section{Smoter Triglavskega narodnega parka}

V prvem vprašanju smo želeli izvedeti poznavanje smotra Triglavskega narodnega parka pri srednješolcih Zavoda za invalidno mladino in mladimi v parku.

Anketirani so menili, da je smoter predvsem varovanje narave in zakonsko varovanje območja kjer naj bi se vsako nepravilno ravnanje sankcioniralo. Nihče od anketiranih domačinov ni omenil, da je Triglavski narodni park namenjen tudi varovanju kulturne krajine, čeprav je bil park ustanovljen tudi z namenom zagotavljanja življenskih pogojev za ljudi, ki živijo v parku, zagotavljanja prometne dostopnosti in kumunalne urejenosti (Zakon o TNP, Ul SRS, 1981, člen 82). Tudi s podpisom Alpske konvencije (1991) naj bi Slovenija zagotavljala nadaljni razvoj gorskih predelov.

\section{Obseg in število prebivalcev Triglavskega narodnega parka}

$\mathrm{V}$ drugem in tretjem vprašanju smo od mladih želeli izvedeti obseg in število prebivalcev v parku.

Pri učencih zavoda opažamo, da pogosto podcenjujejo število prebivalcev $\mathrm{v}$ Triglavskem narodnem parku.

Kljub temu, da so domačini pravilneje opredeljevali obseg parka, pa z njihovo osveščenostjo nikakor ne moremo biti zadovoljni. Anketiranca iz Studorja nista vedela, da leži Stara Fužina v narodnem parku. Anketiranec iz Stare Fužine ni vedel, da je Koprivnik v narodnem parku. 


\section{Poznavanje ogroženih rastlinskih in živalskih vrst Triglavskega narodnega parka}

Po Odloku o zavarovanju redkih ali ogroženih rastlinskih vrst (UL SRS, 1976, 2. Člen) je zavarovane rastline prepovedano uničevati, prenašati iz naravnih rastišč, prodajati in izvažati $\mathrm{v}$ tujino.

Živali so zakonsko zaščitene z zakoni iz leta 1976; Zakon o sladkovodnem ribištvu, Zakon o varstvu, gojitvi in lovu divjadi ter upravljanju lovišč, Odlok o zavarovanju redkih, ogroženih živalskih vrst in njihovih razvojnih oblik.

Po Uredbi o zavarovanju ogroženih živalskih vrst (Ul RS, 1993) je zaščitene živalske vrste prepovedano loviti, ubijati, preparirati, prodajati, posredovati pri njihovi prodaji, kupovati ali darovati, izvažati ali odnašati $\mathrm{v}$ tujino ter namerno vznemirjati $\mathrm{v}$ njihovem življenskem okolju ter uničevati, poškodovati, zbirati ali prenašati njihova gnezda, legla in jajca oziroma njihove razvojne oblike.

Živali zavarovanih vrst ni dovoljeno zadrževati v ujetništvu.

V življenski prostor zavarovanih vrst ni dovoljeno vnašati novih vrst, ki bi lahko ogrozile živali zavarovanih vrst.

Po zakonu o varstvu okolja (Ul RS, 1993) je temeljni cilj varovanja okolja trajno ohraniti vitalnost narave, biološke raznovrstnosti in avtohtonih biotskih vrst.

V Rdečem seznamu (Rdeči seznam ogroženih vrst v Sloveniji, 1992) najdemo tudi vrste, ki so v Triglavskem narodnem parku že izumrle ali jim to v bližnji prihodosti grozi.

V četrtem vprašanju smo želeli spoznati kako mladi poznajo ogrožene rastlinske in živalske vrste.

Rastline in živali so bolje poznali mladi iz Triglavskega narodnega parka. Učenci so slabše poznali predvsem rastline. Planiko je navedlo $70 \%$ domčinov in le $35 \%$ učencev. Trije anketiranci so menili, da je ogrožena žival parka zlatorog. Tudi učenci, ki niso bili anketirani (ponekod celo večina razreda) so bili prepričani o obstoju zlatoroga. 


\section{SKLEP}

Anketni odgovori so prikazali majhne razlike pri poznavanju Triglavskega narodnega parka med učenci Zavoda za invalidno mladino in mladimi iz Triglavskega narodnega parka.

Mladi iz parka so menili, da je park ustanovljen zaradi zaščite narave, opozarjali so na sankcioniranje ne pa na ugodnosti, ki jih park prinaša. Učenci so v parku uvideli tudi vrednoto, ki privablja turiste.

Domačini so se bolje izkazali v poznavanju obsega in števila prebivalcev v parku. Vendar smo ugotovili, da boljše poznavanje parka navadno ne presega Bohinjske kotline.

Nedvomno je, da poznajo mladi iz parka več zaščitenih rastlinskih in živalskih vrst. Učenci so pogosto navajali živali, ki jih v Sloveniji sploh ni. Anketiranci so navedli celo pravljično žival zatoroga.

Vsi anketiranci tako učenci zavoda kot mladi iz Triglavskega narodnega parka ne poznajo dovolj dobro parka. Zavarovana območja, še tako dosledno zakonsko urejena, brez nenehnega osveščanja niso dovolj.

\section{LITERATURA:}

1. Odlok o zavarovanju redkih ali ogroženih rastlinskih vrst, 1976, Uradni list, 2.člen.

2. Odlok o zavarovanju redkih, ogroženih živalskih vrst in njihovih razvojnih oblik, 1976, Uradni list SRS.

3. Uredba o zavarovanju ogroženih živalskih vrst, 1993, Uradni list RS.

4. Uredba o zavarovanju samoniklih gliv, 1994, Uradni list RS.

5. Ustava Republike Slovenije, 1994, Uradni list RS, 71 člen.

6. Velkavrh T.,1996: Okoljska zavest in Triglavski narodni park. Diplomska naloga.

7. Vidic J., 1992: Rdeči seznam ogroženih vrst v Sloveniji. Varstvo narave.

8. Zakon o narodni in kulturni dediščini, 1981 Uradni list SRS, 17 člen.

9. Zakon o sladkovodnem ribištvu, 1976, Uradni list SRS.

10. Zakon o Triglavskem narodnem parku, 1981, Uradni list SRS.

11. Zakon o varstvu okolja, 1993, Uradni list RS.

12. Zakon o varstvu, gojitvi in lovu divjadi ter upravljanju lovišč, 1976, Uradni list SRS. 


\title{
COMPREHENSION OF TRIGLAV NATIONAL PARK
}

\begin{abstract}
Summary
In this year the program Knowledge helps preserving nature is being conducted at Centre for Training of the disabled Youth in Kamnik. The main aim of the program is to acquaint the students and their parents about environmental problems and way of solving them.
\end{abstract}

One can only act in accordance with its natural environment when he or she knows it well. This text has been written based on questionnaire about such knowledge about the only national park in Slovenia.

The data were gathered by questioning among tweny randomly selected students of Centre for Training of the disabled Youth. Later the group of students gathered comparison queries from 20 young, again randomly selected, inhabitants of TNP from three different villages.

The Triglav National Park was by questionnaire's most often pronounced as the area of nature preservation where all wrong doings are penalised. No one of young inhabitants mentioned that the park's goal is in encouragement and support of inhabitants, as it is written in several laws.

The youth living in park area also knew better which places belong to the park and which not, compared to the ones from the students of Centre for Training of the disabled Youth in Kamnik. However this does not imply the good knowledge of park as some were even not certain if the park extends to their nearest neighbours.

The population of park was also better estimated by the youth from park. Students of Institute underestimated it.

The youth from park showed better knowledge on protected account of flora and fauna too. Especially inhabitants most commonly mentioned edelweiss. Some mentioned the famous magic creature Zlatorog (rock goat with gold horns).

In our project we found out that not only the students, but also the youth from TNP, lacks the knowledge of park. We concluded that the sole existence of park does not suffice, we should also take care of education about it. 